\title{
Internet of Things as a Digital Transformation Driver in the Finnish Manufacturing Technology Industry
}

\author{
Kalevi Kettunen and Erno Salmela \\ Lappeenranta University of Technology, Lahti, Finland
}

Correspondence should be addressed to: Kalevi Kettunen; kalevi.kettunen@gmail.com

Received date: 10 March 2017; Accepted date: 23 August 2017; Published date: 29 December 2017

Academic Editor: Anna Lisa Guido

Copyright @ 2017. Kalevi Kettunen and Erno Salmela . Distributed under Creative Commons CC-BY 4.0

\begin{abstract}
The aim of the study was to determine the state and trends of digital transformation in the Finnish manufacturing technology industry and its impact on a company's competitive edge from the perspective of the Internet of Things. The research was conducted as a case study of 15 manufacturing technology industry companies. Data were collected through semi-structured interviews. The results indicate that these technology industry companies consider digital transformation as a necessity. At the moment, the utilisation of the Internet of Things is still in its infancy, and therefore, its business impact is minor. Nevertheless, visions are much more ambitious: companies aim to be trendsetters in their sectors. To achieve such a goal, there is no time to waste. The novelty of this research lies in the fact that no equivalent cross-cutting studies on the Internet of Things have been carried out in the Finnish manufacturing technology industry. As a practical advantage, the study provides information on how the Internet of Things benefits companies taking their first steps towards a digital transformation.
\end{abstract}

Keywords: Internet of Things, Industrial Internet, digital transformation, business transformation

Cite this Article as: Kalevi Kettunen and Erno Salmela (2017)," Internet of Things as a Digital Transformation Driver in the Finnish Manufacturing Technology Industry ", Journal of Innovation \& Business Best Practice, Vol. 2017 (2017), Article ID 623981, DOI: 10.5171/2017.623981 


\section{Introduction}

Finland's trade balance has shown a deficit for five consecutive years. In 2001, the balance was 11910 million euros, but by 2015 it had plummeted to -427 million euros (Statistics Finland web, 2016). The wellbeing of the Finnish national economy depends on foreign trade, and the country's export industry has in recent history strongly relied on the pioneering expertise of manufacturing technology industry companies and the novelty value of innovations. However, globalisation and the upsurge of technical know-how in developing countries have eroded sales in the Finnish manufacturing technology industry due to high manufacturing costs. Digital transformation provides Finnish companies a new opportunity to bridge this price gap and create completely new business through fresh solutions.

Finland has now set its sights on digital transformation as a new driver of the national economy. Actors as influential as the Government have encouraged manufacturing Finnish technology industry companies to invest in digital transformation in an attempt to raise the Finnish economy to a more sustainable level. Even government-owned development funding agencies, such as Tekes - the Finnish Funding Agency for Innovation, finance the digital transformation of businesses (Tekes web, 2016). In the field of digital transformation, the Internet of Things (IoT) presents a new range of business opportunities. It is assessed to increase Finnish business by 1.4 billion euros by the year 2020. Nevertheless, a majority of Finnish manufacturing technology companies have yet to truly seize the possibilities afforded by the IoT (Tekes web, 2016). Digital transformation is seen as a considerable opportunity also in other Western countries. For example, Germany has launched a national project entitled Industri 4.0 with the aim to employ digital transformation to improve the competitiveness of, for example, the manufacturing industry (German Trade \& Investment, 2016).

Digital transformation is known to give a competitive edge to companies at least in theory, but how is it manifest in practice? The aim of this study is to determine the state and direction of digital transformation in Finnish manufacturing technology industry companies and its advantages from the perspective of the IoT.

The article is composed as follows: the next section presents the research methodology, section 3 reviews previous literature on digital transformation and the IoT, section 4 introduces the results of the interviews, and section 5 interprets the results. The article is concluded with a summary and needs for further research.

\section{Implementation of the Research}

The aim of this study was to determine the state and direction of digital transformation in manufacturing Finnish technology industry manufacturers and its importance in terms of success on the global market. The research was limited to external digital transformation and utilization of IoT; that is, the added value manufacturers can produce to their customers through digital transformation and how it can be translated into a competitive advantage. The key

Kalevi Kettunen and Erno Salmela (2017), Journal of Innovation \& Business Best Practice, DOI: $10.5171 / 2017.623981$ 
framework of the study is the IoT and its utilisation as a foundation for value creation.

The research started with a literature review with the central aim to identify key themes involving digital transformation with IoT, which helped to formulate the research questions and plan interviews.

The research sought answers to the following questions regarding digital transformation:

- What does digital transformation with IoT mean in Finnish manufacturing technology industry?

- What are the most common triggers for starting the digital transformation with IoT?

- How has digital transformation with IoT impacted the activity of the business in practice?

- What challenges has digital transformation with IoT presented?

- What competitive edge has digital transformation with IoT provided to manufacturers and has it generated new earnings logics or business models?

The research was conducted as a case study of 15 Finnish technology industry manufacturers and the data were collected through semi-structured interviews. Study group was limited to technology industries of Finland associations defined sub-sector "mechanical engineering / manufacturing industry" (Teknologiateollisuus ry, 2016) later called as manufacturing industry.

The manufacturers studied were selected on the basis that they have own products, own product design and development, international business, head office in Finland and have started digital transformation through IoT aiming to fortify their position in global markets. In the case study group, different size of companies was selected to understand whether the size and turnover have impacts on digital transformation progress or willingness to implement digital elements to their business. Study group companies with employee and turnover figures with sub industries are listed in annex 1.

Representatives of manufacturers were interviewed in spring 2016. One person was interviewed from each company. The interviewees were management team members or in charge of digital transformation e.g. business development directors. One researcher conducted all interviews. Manufacturing companies of different sizes were selected for the interviews to obtain a comprehensive picture of the level of IoT utilization. The number of interviews was limited to 15 because at that point the responses started to repeat themselves, indicating that the saturation point had been reached. The companies that took part in the study are presented in Annex 1.

Semi-structured interviews were selected as the interview method. They suit situations in which information is required on specific topics and interviewees do not need to be given extensive freedom. Semi-structured interviews may be employed when the examined area is not known in detail. The researcher poses open questions instead of multiple-choice ones. In a semi-structured interview, identical or nearly identical questions are posed to all interviewees in the same or nearly the same order. This type of defined and partly open interview is situated between a structured questionnaire and a narrative interview (Hirsjärvi and Hurme, 2001; Hirsjärvi et al., 2000). The interviews consisted of four themes: 
1. The role of IoT in business

2. The impacts of digital business in a company

3. The evolution of digital transformation in a company

4. The reality and future of digital transformation

The interview questionnaire is presented in full in Annex 2.

An individual file was first created for each company interview, and the responses were subsequently compiled into one document and grouped based on the questions. At this stage, any data that did not fall within the delimited research topic were eliminated from the material. Two researchers analysed the data, which were mainly qualitative. Quantitative data were collected only on the size of the companies and the quantity of digital business in relation to other business. A content analysis was carried out by classifying the data into categories.

The aim was to identify the most significant repetitions and deviations. Both researchers first analysed the data independently, after which they established a shared view of the results. Subsequently, both researchers compared the results against the research questions and recorded the key findings related to each question. Finally, the researchers collaboratively interpreted the results and then drew conclusions on the current state, trends and importance of digital transformation in creating a global competitive edge for manufacturing Finnish technology companies.

\section{Literature Review}

This section deals with the key themes of the research questions - digital transformation utilizing IoT and its triggers, and its advantages and challenges - in the light of previous literature.

\section{Digital Transformation}

In this article, digital transformation refers to how digital transformation changes entire business industries and converges industries. Digital cameras are a good example of changes in business. The sales of e-books alongside traditional printed books, on the other hand, are an example of convergence. Transforming companies may need to reinvent themselves to transition to the digital era or even to survive. The company Ifolor, which manufactures photograph products, is a good example of this. One form of transformation is the bundling of products and services by different sectors, creating value to the customer (Ilmarinen and Koskela, 2015). Also network orchestrators in the platform business, such as Uber and Airbnb, are an example of transformation. Their activity is based on the efficient consolidation of supply and demand, including also the creation of new supply and demand (Parker et al., 2016; Libert et al., 2014).

The IoT provides an interactive infrastructure enabling incremental business conversion as well as radical changes in the business environment. Current IoT applications generally focus on enhancing and optimising present processes and related cost reductions within companies and within value chains (Bucherer and Uckelmann, 2011). New application set-ups, sometimes called as smart services and smart technologies, are targeting more revenue generation (Fleisch et al., 2005). Digital business conversion can be seen as a change in organisations utilising digital

Kalevi Kettunen and Erno Salmela (2017), Journal of Innovation \& Business Best Practice, DOI: $10.5171 / 2017.623981$ 
technologies and new business models to enhance performance (Wade, 2015).

In other words, digital transformation is also a matter of disruption. A disruptive innovation is a reform that enables new markets and value chains to disrupt and disturb existing market and value chains, displacing recognised market leading firms and products, including alliances. Market disruption takes place when a service or product fits a new or developing market segment that is not in the interest of existing companies (Christensen, 1997). Disruptive innovations seem to be generated by entrepreneurs or outsiders rather than present market-leading companies (Sims, 2011; Sarasvathy, 2009). The present market leaders do not aim for disruptive innovations because their profitability would decrease at first and because their need for development can take allocated resources away from daily business which are needed in competition with existing competitors (Christensen, 1997). A disruptive innovation may take more time to evolve and involves higher risks than incremental innovation, but then again, it may offer considerably better business opportunities (Marnix, 2006).

Digital transformation and disruption are mirrored in strategic value innovation, which aims for so-called emerging growth. In such cases, the focus is on new business, new technologies and service concepts, and penetrating new markets, which usually require cooperation between different sectors (Prahalad and Krishnan, 2010; Kim and Mauborgne, 2005; Tuulenmäki, 2012; Lusch et al., 2010). Sarasvathy (2009) and Sims (2011) further discuss the market angle and state that markets are not penetrated, but instead, organisations take measures to shape suitable markets together with business partners and customers. The target of strategic value creation is to create new value for different parties of the value system - first and foremost for the customers. To this end, the company must do something else than their competitors, or the same things differently (Tuulenmäki, 2010). Kim and Mauborgne (2005) refer to this as the blue ocean strategy, where in addition to new value, a key role is played also by improved cost efficiency, enabling innovations to reach large customer masses faster.

\section{Internet of Things}

Digital transformation refers in this article to the Internet of Things or the Industrial Internet of Things, which is used in industrial conditions and refers to sensors attached to objects and machines to transmit information to the Internet. The data on the Internet are utilised in different services (Ilmarinen and Koskela, 2015). As noted by Ashton (2009), the term IoT, developed in 1999, initially meant to describe the following situation:

Today computers - and, therefore, the Internet - are almost wholly dependent on human beings for information. The problem is, people have limited time, attention and accuracy - all of which means they are not very good at capturing data about things in the real world. We need to empower computers with their own means of gathering information, so they can see, hear and smell the world for themselves.

As a result, the IoT provides a linked set of software and sensors that do not experience the same limitations as people. However, in some contexts it seems that the IoT is starting to be shaped to include inputs from 
humans who are linked to the Internet. Ultimately, this is being referred to as the Internet of Everything (e.g. SRA, 2009). Chui et al. (2010) define the IoT as sensors and actuators embedded in physical objects from roadways to pacemakers - linked through wired and wireless networks, often communicating with the same Internet Protocol as the Internet. The IoT commonly refers to the concept that many different things are connected to the Internet and consequently can be connected to each other. Such things can include software, sensors, devices or databases.

\section{Degrees of utilisation of the IoT}

The importance of the IoT usually increases in stages. First, devices are remote controlled, or data from individual devices are utilised to optimise the use and maintenance of the devices. At the next level, customers are assisted in optimising their entire production process using the data. The following step is to help the customer to develop his or her business, which requires a profound understanding of the customer's business. The final level involves combining data from different customers. A large quantity of data enables learning new things and innovating (Ilmarinen and Koskela, 2015).

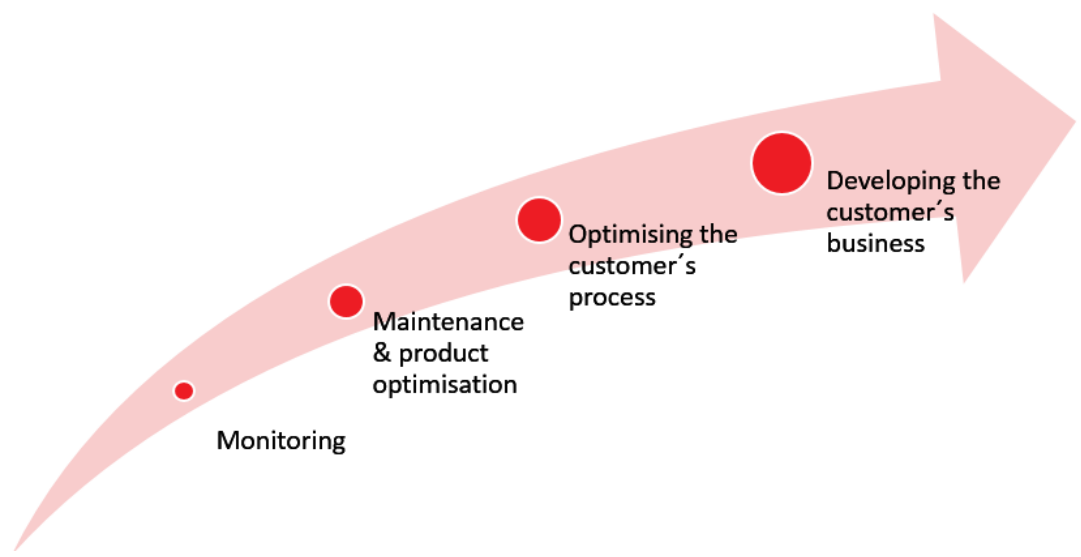

Fig. 1: Degrees of utilisation of the IoT (Ilmarinen ja Koskela, 2015).

The level of utilisation of the IoT is affected by major changes in three areas: technology, markets, and customer behaviour (Figure 2). Even though technology enables progressive solutions, only the reception by markets and customers determines the creation of new business (Ilmarinen and Koskela, 2015).

Kalevi Kettunen and Erno Salmela (2017), Journal of Innovation \& Business Best Practice, DOI: $10.5171 / 2017.623981$ 


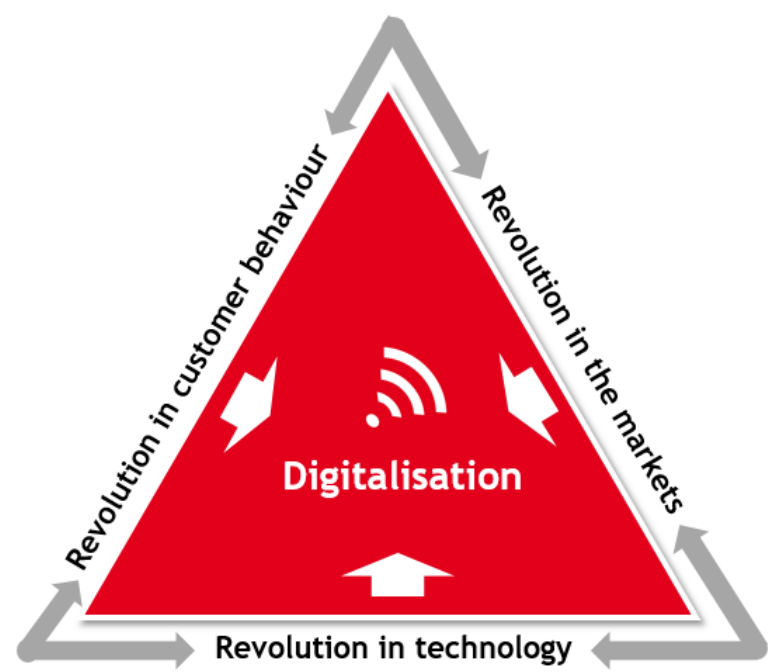

Fig. 2: Major changes related to digital transformation (Ilmarinen and Koskela, 2015).

\section{Reasons for initiating a digital transformation and the business advantages of the IoT}

The reasons for starting a digital transformation are wide-ranging. In some cases, it means focusing on the customer, as customers are currently more aware of their options than before. In fact, customers actively seek better and higher-quality services at lower prices - services that solve their problems more efficiently. On the other hand, the need for change may stem from changes in the competitive arena, forcing a company to follow the path of its competitors (Wade, 2015).

The benefits of digital transformation and the IoT to companies can be seen in the following order of importance:

1. Generating new business for existing products and services;

2. Creating new working approaches and business processes;

3. Modifying the existing business model and strategy;
4. Starting a new wave of innovation;

5. Lowering the cost structure.

(The Economist Intelligence Unit, 2013)

Sun et al. (2012) see the advantages as follows:

1. Enabling companies to gain first-mover advantage during the development of the IoT

2. Speeding up the pace of transformation or strategic realignment to meet the challenges of the IoT

3. Better seizing of opportunities in the IoT

The IoT also lays the groundwork for completely new business models in industrial enterprises. Bucherer and Uckelmann (2011) introduce four different business models in their research:

\section{Scenario 1: Product as a Service (PaaS)}

The change from providing products to providing services is a major trend in business model innovation. Not only do software companies provide PaaS instead of selling software licenses, but also more traditional manufacturers pursue this way. 


\section{Scenario 2: Information Service Providers}

If information can be measured and invoiced, new business opportunities for information service providers will be possible. IT departments can become profit centres instead of cost centres. Data centres can provide processing services in addition to storage space for IoT-related data. Additionally, information service providers can aggregate and process information from different sources, thus providing a higher value of information.

\section{Scenario 3: End-user Involvement}

The IoT offers a new level of consumer integration into co-creation processes. While "living labs" have been used to integrate limited user groups into product and service development at a certain stage in the product life cycle, the IoT will link all consumers across the life cycle of a product. Companies that will know how to utilise this huge potential will be in the lead for new business models in B2C scenarios.

\section{Scenario 4: Real-time Business Analysis and Decision-making}

Real-time business analysis capability remains a core requirement of each enterprise, as it provides the basis for agile management strategies.

Based on the research by Dijkman et al. (2015) and Morris et al. (2005), the most important element in the IoT business model is the value proposition. The elements of a value proposition include e.g. performance, updatability, comfort and usability. The following important elements in the IoT business model are customer relations and key partners. The value proposition is understandably the most important one, as it introduces benefits to the user of the service or product. Key partners in the IoT are software developers, data analysts and equipment suppliers (Dijkman et al., 2015).

\section{Challenges of introducing the Internet of Things}

The Economist Intelligence Unit (2013) has stated that the greatest challenges in the IoT transformation are: 1. a lack of employee skills and expertise, 2. a lack of knowledge or commitment shown by management 3. no explicit IoT element in the products, 4 . the immaturity of industrial standards, and 5 . the high costs of building an IoT infrastructure.

\section{Qualitative analysis of interview data}

This section presents the research results categorised according to the research questions.

\section{Digital transformation and the IoT in manufacturing Finnish technology companies}

Digital transformation did not have an explicit definition in the target companies. This is partly explained by the fact that some of the companies started their transformation a decade ago. These companies felt that digital transformation is not a separate entity - it was embedded into their everyday operations. In a majority of the companies, digital transformation referred to the utilisation of the IoT in the remote monitoring and control of devices sold to customers, data collection, analytics, and solving customer problems remotely. Companies that had started the digital 
transformation of their business within the past few years considered digital transformation as an external phenomenon and as the creation of digital services to customers. Companies which were further along in their digital transformation had generated entities that served the company itself as well as customers wide-ragingly.

The turnover did not play a significant role in the desire to undertake digital transformation. Small and medium-sized enterprises saw digital transformation as a necessity for continuing their business. Large established businesses considered digital transformation more as a means to develop their service business and value added services. As a rule, younger businesses had already incorporated digital elements into their products, which was primarily seen as a way to increase sales and secondarily as a supplementary service opportunity.

In the companies in the study, the number of employees and the turnover varied considerably. Companies with similar staffs and turnovers seemed to adopt similar operating models. Digital transformation know-how in younger companies was relatively at a significantly higher level than in older companies. Furthermore, smaller companies dedicated more resources to digital transformation in relation to their turnover than larger companies. The importance of digital transformation was thus more pronounced in smaller and younger companies.

\section{Reasons for Digital Transformation}

Companies' reasons for digital transformation were rather alike. The companies in the study mentioned three different reasons for digitalising their business:

1. Company needs (80\%)

2. Customer needs (66\%)

3. Differentiation from competitors and survival (53 \%)

Company needs related to the service business, product development, and in some ways also customer satisfaction. Digital transformation was a tool for ensuring that the company was aware of whether their product functioned as expected in the customer's use, and that maintenance needs could be addressed as well as possible. Also the location of equipment and facilities affected the digital transformation decision. The companies' end-products could be located in rural areas difficult to access, making a remote connection the only commercially viable way to provide service to the customer.

Customer needs also clearly steered the digital transformation of companies. Some of the enterprises had received explicit requests and development proposals from their customers, which initiated the digital transformation process. In these cases, the companies had created a profound development relationship with the customer to ensure that the product or service met the customer's needs as well as possible. Such experimental product development and pilot projects had also facilitated future projects in bidding competitions when new sales arguments were needed.

Differentiation from competitors was the third significant driver of digital transformation. Companies considered that price competition was no longer possible with the Finnish cost structure. Companies 
saw great opportunities in regaining lost market shares with the help of digital transformation. On the other hand, some businesses considered digital transformation as a prerequisite for maintaining their current market position. The service business was seen as an important opportunity also in this respect, as differentiation from competitors with new service products would be clearer and would help to develop new business.

\section{Impacts of Digital Transformation on Business Operations}

Digital transformation has changed development processes in companies in a variety of ways. For example, the execution of Scrum-based development processes has accelerated entry into markets and decreased costs. Results have been promising especially in product development because big data have been available on products for a significant amount of time, enabling the development of devices and their functionalities in novel ways.

The development process was also stated to have become more agile and innovative and to reach outside organisations. Most companies planned to involve customers in the development process at an earlier stage to understand what the customer actually considers important and desirable. In fact, digital transformation has led to the increase of experimental product development and pilot projects with customers. Digital transformation was also stated to have increased the possibilities to test new operating models, and failure was no longer considered a major obstacle. Digital transformation had also created new jobs in the companies, and as a result, the new employees and the know-how they brought with them had changed practices in the companies.

Half of the companies experienced that digital transformation had changed their company culture very little or not at all. However, the remaining half considered that their corporate culture had been revived and modernised, and the atmosphere in the company had become more positive. This can be explained by the company's degree of digital transformation. All companies that implemented the changes described above had started their transformation a long time ago or were young enterprises. In such cases, the adaptivity of digital transformation was easier - even a given.

Nearly all enterprises considered that digital transformation had increased their brand value. Digital transformation had helped companies to differentiate themselves especially from competitors in countries of low-cost production with a new, modern and more innovative corporate image. All of the companies in the study had had lengthy problems in competing with the price level in these countries - especially since their product quality had been approaching the Western quality. When the price difference is tens of per cent, the only alternative is to provide added value to the customer.

The presence of digital transformation in the company strategy varied a great deal in the companies participating in the study. One explanation is the initial timing of adopting digital elements in the business. It seems that companies which had invested in digital business for considerably longer did not have a separate digital strategy. Instead, they had embedded digital transformation into their business strategy. More than half (8 out 
of 15) of the companies had defined their digital business in the product area, product development, technology, and service business strategies under the main business strategy. Four companies had not described digital business in their strategy, but had qualified it as their key development area.

\section{Challenges of Digital Transformation}

The companies faced very similar challenges. 11 companies (73\%) experienced that a lack of expert resources was the single greatest problem in digital transformation. The second challenge was customer maturity regarding digital transformation (9 companies, $60 \%$ ). All companies conducted international business, and the receptivity of customers varied considerably from one market area to another. The third significant challenge (7 companies, $53 \%)$ was the organisation's internal digital transformation; in other words, the organisation's ability to adopt and commit to digital transformation, which directly affected the speed of the transformation in the company. This was most conspicuous in conventional operating environments, where the employee turnover was low and the history of the company long.

The commitment of the management was considered to play a key role in a successful transformation. The fourth most frequent challenge (5 companies 33\%) was a lack of new earnings logics, and translating the usefulness of the services to the customer and digital transformation into long-term business. The fifth challenge involved intellectual property questions; that is, the ownership and confidentiality of data. Some customers were reluctant to disclose data on the use of equipment, invoking nondisclosure obligations.
A majority of the companies considered that their digital transformation had progressed more slowly than anticipated. The goals had been overly optimistic and digital transformation had been expected to be a greater commercial driver. The process had been decelerated firstly by the customers' insufficient preparedness to adopt new services and technology. The second reason was the fact that productising technology, building new services and developing new earnings logics had been more challenging than anticipated. None of the companies considered they were ahead of the schedule they had set for themselves. Also the production of digital services on a commercially sensible scale was considered challenging across the board.

\section{Digital Transformation as a Source of Competitive Advantage}

The companies in the study saw digital transformation as an important future development project nearly without exception. The companies considered digital transformation to have generated a competitive advantage in three respects:

1. Increased product sales

2. Increased service business

3. Improved corporate image (66\%)

The clearest individual factor was the increase in product and equipment sales and maintaining or increasing the company's market share. Half of the businesses felt that without digital transformation, their turnover would not be at the level it is today. The digital features have also made it possible to offer new services utilising the IoT. Improving the company's image in the eyes of the customers was also considered a competitive advantage. Some of the 
companies felt that they became more interesting as equipment suppliers because the digital transformation branded them as forerunners.

Companies have produced added value to customers through digital transformation; in other words, mainly by providing new product features and digital services. Some of the companies had been able to create full-scale service platforms which could comprehensively monitor, optimise, analyse and boost the operation of products and devices. Some companies offered mobile applications and other new types of user interfaces where the service business was connected to the equipment and was easily available and usable to the customer.

Other companies also offered 24-hour remote monitoring to provide the customers with a maximum return on their investment. On the widest possible scale, companies may offer asset management services for the entire life cycle of the product, deriving maximum efficiency during the product's life cycle. The IoT and big data integrated with real-time analytics has created significant added value to customers.

Some businesses have created novel earnings logics, but their share of the total turnover of companies remains only minor. The new earnings logics were based on the above-mentioned remote monitoring, analysis and diagnostic services. Companies which were able to offer digital value-added services comprehensively throughout the product life cycle were able to generate the greatest efficiency.

Digital transformation had created very little completely new business or earnings logics for the companies. It had primarily boosted the growth of existing product and service business. The respondents assessed that the digital business ranged between 0.1 and 3\% of the turnover. However, digital business is difficult to measure very accurately on its own. Especially distinguishing it from service business has been difficult. It is more easily distinguished when customers are sold software and other tools or information.

\section{Discussion}

The Finnish and more widely the Western European technology industry have strived to be technological pioneers and strategically aware of the future. This study indicates that digital transformation in the manufacturing Finnish technology industry is a primary development target which aims to improve the competitiveness of businesses on the global market. The manufacturing Finnish technology industry expects a great deal from digital transformation, especially in terms of new service products and earnings logics. The study showed that the digital transformation of service business also enables disruptive innovations. Creating them requires first and foremost a visionary and bold approach to renewal. When the study was conducted in 2016, most of the digital services and earnings logics of the companies nevertheless focused on remote monitoring, analysis and diagnostic services. In other words, the companies still operated at the beginning of the digital development cycle (cf. Figure 1).

The reasons for engaging in digital business are in line with earlier studies, such as the ones by The Economist Intelligence Unit (2013) and Sun et al. (2012). However, the manufacturing Finnish technology industry strongly highlights the fact that businesses have long needed to develop into

Kalevi Kettunen and Erno Salmela (2017), Journal of Innovation \& Business Best Practice, DOI: $10.5171 / 2017.623981$ 
technological pioneers in terms of their products to gain a competitive advantage. Now Finnish companies are facing a new challenge, and they are taking it seriously, recognising the opportunity to become technological pioneers through digital transformation. They also see the great business risks in not pursuing this.

The study indicates that the challenges of digital transformation do not depend on technical solutions, which were considered rather easily solved through engineering work (86 \% of the companies). The key challenge in executing a digital transformation involved the company's internal and external mindsets and operating models. As also previous studies (e.g. The Economist Intelligence Unit, 2013) show, especially the commitment and expertise of the management are a prerequisite for a successful transformation. Also competent external resources played an important role in the transformation of the companies examined. The study also indicated that one of the greatest obstacles to digital transformation was immaturity within the company towards the transformation.

Ilmarinen and Koskela (2015) state that digital transformation requires changes in customer behaviour, a revolution in technology, and changes in markets. The present research confirmed this, but manufacturing Finnish technology companies are not waiting for changes in markets. Instead, they are seeking firstmover advantages, as Sun et al. (2012) suggest. In other words, the Finnish technology industry is pursuing and creating a market disruption through strategic value creation.
The study showed that pioneering companies aimed to change their operating models and earnings logics towards valuebased trade or the Product as a Service (PaaS) business model, as Bucherer and Uckelmann (2011) propose. The PaaS model is no longer a theoretical framework in conventional business. Instead, it is a clear aim for some pioneering companies. On a larger scale, this business model may provide pioneers with a disruptive oligopoly for part of the capital goods market. Valuebased pricing aims to define the costs of the production and distribution of a service and their value to the customer. In such cases, the value is determined directly e.g. as the output of the customer's process, such as processed tonnes.

However, the problem in value-based pricing is the difficulty to determine the added value to the customer (Nagle and Holden, 2001; Apilo et al., 2009). Therefore, service providers should continue to invest more in interaction with customers to gain a better understanding of how the customer benefits from the service. However, this is not possible simultaneously in all markets. For example, in the chemical industry, customers are cautious about explicating their activity. In fact, the lack of openness seems to be a key challenge in value-based pricing.

\section{Managerial Implications}

The research helps companies starting their digital transformation to focus on the right issues and avoid problems along the way. The industrial arena and markets of digital transformation are changing more rapidly than ever. The company's vision and courage to start a transformation determine whether the IoT is an opportunity or a threat to it. Conventional business models will change 
and demand efforts and rapid development from companies to ensure future competitiveness. The study reveals the potential of digital transformation and its importance to the Western, high price level technology industry. Digital transformation also enables improving the brand value of the company as an innovator and pioneer.

The study suggests that digital transformation does not necessarily require great financial or human resources, but nevertheless, skilful people play an important role. As the IoT is a rather new phenomenon, many companies have had difficulties finding suitable employees. On the other hand, companies have considered it useful to expand their networks and acquire expert staff through reliable partners. However, a majority of the companies had executed the digital transformation on their own. Subsequently they felt that partners with flexibility and a certain specialisation would have executed the transformation faster and with significantly lower costs. On the other hand, many companies pointed out that digital transformation had enriched their corporate culture. Companies had experimented more, become more focused on facts and more innovative, and involved their partners more.

The new earnings logics enabled by digital transformation open more opportunities for technology industry companies. Companies in the manufacturing industry strive to reduce their invested capital and wish to change their capital expenditures (CAPEX) to operating expenses (OPEX) in the sales of capital goods and thus minimise their invested capital. Digital transformation creates a scenario where the traditional capital goods market can be transformed into value-based sales, selling only the end product that customers want from their process. A concrete example is the industrial pump market where, instead of the actual product or pump, the customer purchases cubic meters of pumped substance. In other words, attention is shifted from exchange value and ownership to the utility value to the customer, which e.g. Nenonen and Storbacka (2010) consider a trend to pursue. New business such as the above is possible with the IoT, as it enhances transparency between the producer and the customer. This also enables value-based pricing, where the generated value is divided between the service-provider and customer (Tikka and Gävert, 2014; Nenonen and Storbacka, 2010).

The disruptiveness of the business model above offers new competitive tools to the technology industry, which competes with countries with a lower level of costs. Countries with a high cost level can achieve a maximum competitive advantage only if they move quickly in the development of new devices and services. Maintaining a competitive edge in this day and age is becoming increasingly difficult because the know-how in developing countries is on the rise. In addition to disruptiveness, digital transformation can give old products a facelift, allowing companies to create new markets for them with low design costs. However, the emphasis of digital transformation is, at least in the manufacturing Finnish technology industry, no longer on the improvement of existing processes, as Bucherer and Uckelmann (2011) state. Companies primarily develop new products with digital features and entirely new digital service business around their existing product infrastructure. 


\section{Summary and Need For Further Research}

This study examined the digital transformation with IoT of manufacturing Finnish technology companies. The study was based on semi-structured interviews with 15 Finnish technology companies. The companies selected for the study represented different sizes, and their turnovers varied from roughly 5 billion euros to roughly 19 million euros. The research was limited to external digital transformation; that is, the added value technology enterprises can produce to their customers through digital transformation and how it can be translated into a competitive advantage. The key framework that emerged in the study was the IoT and its utilisation as a foundation for new business models and value propositions. As a byproduct of digital transformation, also the corporate culture and practices were reformed.

The study provided a cross-section of the state, direction, challenges and advantages of the Finnish technology industry. On the one hand, the study yielded new knowledge on the practical implementation of the IoT in conventional industry, and on the other, it confirmed previous knowledge. The study also provided valuable data that can encourage companies to initiate a digital transformation. No equivalent studies have previously been conducted in Finnish technology industry companies.

As the research was conducted on businesses operating in the Finnish technology industry, internationally it only has reference value. Additional research in other Nordic countries would create an interesting entity on digital transformation in the Scandinavian technology industry.
This article provides an opportunity to repeat this study in other countries.

Further research on digital business would be needed also in the service business sector and on the consumer markets. A crossdisciplinary research on the development of digital service business in industry from the perspectives of the service sector and consumer markets might help to identify disruptive digital service models and earnings logics that are also applicable to traditional industry. The impact of consumerisation on the operational needs and models of industry is also worth studying. The research would help to identify new business models that could be adapted from the consumer markets to industry. Another worthwhile research topic from the industry perspective would be platform business led by network orchestrators, which has grown strongly on the $\mathrm{B} 2 \mathrm{C}$ side.

\section{References}

- German Trade \& Investment (2016) INDUSTRIE 4.0 - Smart Manufacturing for the Future, available at: http://www.gtai.de/GTAI/Navigation/EN/I nvest/Service/Publications/businessinformation,t=industrie-40--smartmanufacturing-for-thefuture,did=917080.html, read: August 26. 2016.

- Ashton, K. (2009) That 'internet of things' thing, RFID Journal, Vol. 22, pp. 97-114.

- Balta-Ozakan, N., Boteler, B. and Amerighi, O. (2014) European smart home market development: public views on technical and economic aspects across the United Kingdom, Germany and Italy, Energy Research and Social Science, Vol. 3, pp. 6577.

Kalevi Kettunen and Erno Salmela (2017), Journal of Innovation \& Business Best Practice, DOI: $10.5171 / 2017.623981$ 
- Bucherer, E. and Uckelmann, D. (2011), Business Models for the Internet of Things, In: Uckelmann, D., Harrison, M. and Michahelles, F. (eds) Architecting the Internet of Things, pp. 253-277.

- Christensen, C. M. (1997) The innovator's dilemma: when new technologies cause great firms to fail, Boston, Massachusetts, USA: Harvard Business School Press.

- Chui, M., Loffler, M. and Roberts, R. (2010) The Internet of Things, McKinsey Quarterly, Vol. 2, pp. 1-9.

- Dijkman, R.M., Sprenkels, B., Peeters, T. and Janssen, A. (2015) Business models for the Internet of Things, International Journal of Information Management, Vol. 35 No. 6, pp. 672-678.

- Fleisch, E., Christ, O. and Dierkes, M. (2005) Die betriebswirtschaftliche Vision des Internets der Dinge. In: Fleisch, E. and Mattern, F. (eds.) Das Internet der Dinge, Springer, Berlin, Heidelberg.

- Hirsjärvi, S., Remes, P. \& Sajavaara, P. (2000) Tutki ja kirjoita, Helsinki: Kirjayhtymä.

- Hirsjärvi, S. and Hurme, H. (2001) Tutkimushaastattelu. Teemahaastattelun teoria ja käytäntö, Helsinki: Yliopistopaino.

- Ilmarinen ja Koskela, 2015, Digitalisaatio, Yritysjohdon käsikirja, Talentum.

- Kim, W.C. and Mauborgne, R. 2005, Blue Ocean Strategy: How to Create Market Space and Make the Competition Irrelevant, Harvard Business School Publishing Corporation, Boston, MA.

- Libert, B., Wind, Y. and Megan Beck, M. (2014), What Airbnb, Uber, and Alibaba

- Sarasvathy, S. (2009) Effectuation: Elements of Entrepreneurial Expertise, Edward Elgar Publishing.

- Sims, P. (2011) Little Bets: How Breakthrough Ideas Emerge from Small Discoveries, Free Press.

- SRA (2009) The Internet of Things Strategic Road Map, available at: http://sintef.biz/upload/IKT/9022/CERP-
Have in Common, Harvard Business Review, available at https://hbr.org/2014/11/whatairbnb-uber-and-alibaba-have-in-common, read: August 25. 2016.

- Lusch, R., Vargo, S. and Tanniru, M. (2010) Service, Value Networks and Learning, Journal of the Academy of Marketing Science, Vol. 38 No.1, pp. 19-31.

- Marnix, A. (2006) Inhibitors of disruptive innovation capability: a conceptual model, European Journal of Innovation Management, Vol. 9 No. 2, pp. 215-233.

- McCauley, J. (2016) The 4 main challenges for the Internet of Things, available at: http://www.creativebloq.com/hardware/4main-challenges-internet-things-61621076, read: August 26. 2016

- Morris, M., Schindehutte, M. and Allen, J. (2005) The entrepreneur's business model: toward a unified perspective, Journal of Business Reseaech, Vol. 58 No. 6, pp. 726735.

- Nenonen, S. \& Storbacka, K. 2010. Markkinamuotoilu. Johdatko markkinoita vai johtavatko markkinat sinua?, Hämeenlinna, WSOYpro.

- Parker, G.G., Van Alstyne, M.W. and Choudary, S.P. (2016) Platform Revolution, W.W Norton \& Company, Inc., United States of America.

- $\quad$ Prahalad, C.K and M.S. Krishnan, M.S. (2008) The New Age of Innovation: Driving Cocreated Value Through Global Networks, McGrawHill.

IoT\%20SRA_IoT_v11_pdf.pdf, read: October 10.2016.

- Sun, Y., Yan, H., Lu, C., Bie, R. and Thomas, P. (2012) A holistic approach to visualizing business models for the internet of things, Communications in Mobile Computing, Vol. 1 No. 4, pp. 1-7.

- Tekes web, 2015, Teollinen Internet, available at: www.tekes.fi/nyt/tapahtumat-

Kalevi Kettunen and Erno Salmela (2017), Journal of Innovation \& Business Best Practice, DOI: $10.5171 / 2017.623981$ 
2015/teollinen-internet-2015, read: 4.5.2016

- The Economist Intelligence Unit, (2013) The Internet of Things Business Index, A quiet revolution gathers pace, available at: http://www.arm.com/files/pdf/EIU_Interne t_Business_Index_WEB.PDF, read: August 29. 2016

- Teknologiateollisuus ry, available at: http://teknologiateollisuus.fi/en/technology -finland/mechanical-

engineeringmanufacturing-finland, read: 3.4.2016

- Tikka, V. ja Gävert, N. (2014) Arvonluonnin uusi aalto. Näin rakennetaan tämän vuosisadan arvokkaimmat yritykset, Tekeskatsaus 309/2014, Helsinki.

- Tilastokeskus-web, Tuonti, vienti ja kauppatase, available at: http://www.stat.fi/tup/suoluk/suoluk_koti maankauppa.html\#tuonti,vientijakauppatase , read: October 10. 2016

- Tuulenmäki, A. (2012) Lupa toimia eri tavalla, Talentum.

- Wade, M. (2015) Digital Business Transformation. A Conceptual Framework, available at: http://www.imd.org/globalassets/dbt/docs /framework, read: October 10. 2016.

Annexe

ANNEX 1: Interviewed companies

\begin{tabular}{|c|c|c|c|}
\hline Company & Turnover (M€) & Personnel & Sub industry \\
\hline $\begin{array}{l}\text { Lahti Precicion } \\
\text { Oy }\end{array}$ & 21,6 & 152 & Dozing machinery \\
\hline Junttan Oy & 45,6 & 150 & Construction machinery \\
\hline Oilon Group & 96 & 350 & Energy technology \\
\hline Ponsse Oyj & 366,5 & 723 & Forestry machines \\
\hline $\begin{array}{l}\text { Kumera Drives } \\
\text { Oy }\end{array}$ & 23 & 131 & Industrial drives \\
\hline Tana $0 y$ & 19 & 27 & $\begin{array}{ll}\begin{array}{l}\text { Waste } \\
\text { technology }\end{array} & \text { management } \\
\end{array}$ \\
\hline Wärtsilä Oyj & 5029 & 18800 & Energy Technology \\
\hline Chiller Oy & 22,2 & 56 & Air conditioning systems \\
\hline Kemppi Oy & 84,8 & 398 & Welding machines \\
\hline Rocla Oy & 89,2 & 289 & $\begin{array}{ll}\text { Lifting and handling } \\
\text { equipment }\end{array}$ \\
\hline Normet Oy & 54,2 & 269 & Mining machinery \\
\hline Outotec Oyj & 1201 & 4859 & Mining technology \\
\hline $\begin{array}{l}\text { Huurre Finland } \\
\text { Oy }\end{array}$ & 21,6 & 130 & Cooling systems \\
\hline Raute Oyj & 112,5 & 427 & Forest industry machinery \\
\hline Flowrox 0y & 23,8 & 83 & Flow control solutions \\
\hline
\end{tabular}

ANNEX 2: Semi-structured questionnaire

Kalevi Kettunen and Erno Salmela (2017), Journal of Innovation \& Business Best Practice, DOI: $10.5171 / 2017.623981$ 


\section{The role of digital transformation in business}

What does digital transformation and digital business mean in your company?

Why did you decide to digitalise your business?

When did you make the decision? What/who made the decision?

Who is heading the digital transformation? How do the upper management and board see the importance of digital transformation? How would you characterise the role of digital transformation in your company's development projects overall?

How is digital transformation present in your company strategy?

Has digital transformation created completely new business? Or has it led to a transformation - the "revitalisation" of the company's existing business with digital services?

What new business has emerged as a result of digital transformation, and what is its share of the total turnover?

\section{The impacts of digital business in a company}

How has digital transformation changed the operation and culture of your company?

Has digital transformation given your company a competitive edge?

Has digital transformation been an advantage to your company?

Has digital transformation created added value for customers? How do you measure added customer value?

Have you established new earnings logics as a result of digital transformation? What kinds?

Do you sell information? If you do, how have you priced it?

What costs has digital transformation generated for you? (E.g. percentage of R\&D expenses)

Do you consider digital transformation to have increased or decreased jobs in your company? What will be the impact in 2020 ?
How and how much (percentage) has your stakeholder network grown as a result of digital transformation?

\section{The impacts of digital business in a company}

How does your company survey the digital transformation needs of customers?

Has digital business changed your development process (e.g. speed and engaging customers)?

What have been the 3-5 greatest challenges in digital transformation? Which one was the greatest? What has gone without a hitch?

How have the technical solutions been executed? (E.g. connection to the Internet of Things etc.)

Have you had enough competent resources within the company? How have you developed staff expertise? Have you engaged outside consultants?

Have you sought or will you seek funding to implement digital transformation? (E.g. Tekes)

\section{The reality and future of digital transformation}

What have been the 3-5 most important factors in your digital transformation? Which one was the most important?

Looking back on the transformation, how close to / far from your original intent is the outcome? Give an example.

In hindsight, what would you have done differently?

What steps will you take next? 